who differs from Lillie in considering that there is no recovery after the depolarisation as there is in nerve, muscle and certain plant cells. Confirmatory evidence of this has been produced by Gray ${ }^{3}$, who has shown that fertilised sea-urchin eggs have a higher conductivity than unfertilised eggs. (These results have recently been criticised on theoretical grounds by Cole ${ }^{4}$.)

One of us (V. R. $)^{5}$ has shown that the activation of the unfertilised frog's egg by trauma is associated with the propagation of an action potential over the egg surface. The action potential differs from that found in nerve or muscle in that there is no recovery phase.

We have continued these experiments, substituting a spermatozoon for the micro-needle. Two electrodes held in two Péterfi ${ }^{6}$ micro-manipulators were placed at opposite poles of the animal pole of the frog's egg ; localised fertilisation near one (grid) electrode was effected by means of a micro-pipette filled with sperm held in another Péterfi micro-manipulator. The electrodes were connected to a Matthews ${ }^{7}$ oscillograph used in conjunction with resistance. capacity-coupled amplification.

There are strong indications that the attachment of the spermatozoon to the egg results in an action potential being propagated over the egg surface, the action potential again being characterised by having no recovery phase. The change is considerably slower than that observed in stimulated nerve or muscle, and for this reason capacity-coupled amplification is unsatisfactory, as the rate of discharge of the coupling condensers is great compared with the rate of change of the action potential. Considerable distortion is therefore inevitable.

We propose to continue these experiments during the next frog-breeding season using battery-coupled amplification in order to obtain quantitative data. T. PÉTERfi.

V. ROTHSCHILD.

Sub-department of Experimental Zoology, Cambridge.

March 25.

${ }^{1}$ R. S. Lillie, Biol. Bull., 17, 188: 1909

${ }^{2}$ J. Gray, Quart. J. Mic. Sci., 66, $419 ; 1922$.

J. Gray, Phil. Trans. Roy. Soc. B 207, 481; 1916.

K. S. Cole, J. Gen. Physiol., 12, 37 ; 1928.

Tro be published in the near future.

'T. Péterfl, "Handb. Biol. Arbeitsmeth. (Abderhalden)", 5, 479 ; 1923.

B. H. C. Matthews, J. Physiol., 65, 225 ; 1928.

\section{Response of the Leech to Acetylcholine}

THE work of Dale, Feldberg and others shows in a striking way that, in the Vertebrata, excitation is transmitted from nerve to effector through the mediation of either acetylcholine or of adrenalin, according to the mode of innervation ${ }^{1}$. A sensitive test employed for the presence of acetylcholine is its power to cause contraction of the longitudinal muscle of the body-wall of the leech Hirudo medicinalis. I wish to direct attention to the fact that this sensitivity of leech muscle completes a very remarkable picture disclosed by J. F. Gaskell ${ }^{2}$.

In the leech and other annelids, the nervous control of the vascular and the 'voluntary' muscular systems shows a detailed parallelism to these same systems in the Vertebrata. In Hirudo, the contractile blood-vessels receive a double innervation of accelerator and depressor nerves which modify their rhythm. Adrenalin accelerates the rhythm, and the central nervous system contains chromaffine cells analogous to those of the vertebrate sympathetic. In the same way, the vago-mimetic drug muscarin depresses the rhythm, and this action is antagonised by atropine.

The longitudinal and circular muscles of the body-wall do not respond to adrenalin, and can be paralysed by curare. This evident parallel to vertebrate skeletal muscle is now completed by the responsiveness of the muscle to acetylcholine.

A physiological similarity of such intricacy between members of such distant phyla as the Vertebrata and the Annelida is most impressive. It seems possible that 'cholinergic' and 'adrenergic' transmission of excitation demonstrated in vertebrates may be widespread among the colomate phyla, a view supported by the general similarity of action of adrenalin and other drugs among different animals.

Zoological Laboratory, Cambridge. April 26.

${ }^{2}$ Dale, H., Brit. Med. J., 29, 38271934. ${ }^{2}$ Phil. Trans. Roy. Soc., B, 205, 153; 1914.

\section{A Tame Platypus}

MoRE than a year ago I recorded the successful rearing of a platypus by Mr. R. Eadie at Healesville, Victoria $^{1}$; the animal has now been in captivity 740 days. It was probably five months old when captured, and was then 15 inches long and weighed 48 ounces avoirdupois. It is now 21 inches long and weighs 72 ounces. Its daily diet is 18 ounces of worms and two eggs, specially prepared. During the period of captivity it has consumed 700 pounds of worms and 1,300 eggs, most of them duck eggs. It has also eaten thousands of tadpoles and large quantities of grubs. Whether this is a balanced diet or whether in the wild state it finds something else to eat remains to be investigated. But the success of the experiment so far seems unique.

It is still more satisfactory to note that, owing to the protection given and the interest taken, the platypus in the streams appear to be increasing in number. Mr. Lewis, chief inspector of fisheries and game, is to be congratulated on the effective protection afforded.

\section{3-105 Collins Street, Melbourne, C.1.} Feb. 25 .

${ }^{2}$ NATURE, 132,$446 ; 1933.133,260 ; 1934$.

\section{Sounds Made by Fishes in the East Indies}

I WAS interested to read the notes on this subject in NATURE of November 17, 1934, and March 16, 1935.

Although I have not heard the sound made by Therapon, whilst collecting in Singapore waters some years ago $\mathrm{I}$ was introduced to a similar phenomenon caused by fishes of the family Scionidoe (probably of the genus Otolithus). The Malay name of these fishes is gelama. The first time I heard these sounds I was in the company of Mr. W. Birtwistle, of the Malayan Fisheries. The best results were obtained by applying the ear to the rail of the launch. The sounds might be described as a 'chirping' or intermittent hum. 